\title{
Impact of Welfare Benefit Sanctioning on Food Insecurity: a Dynamic Cross-Area Study of Food Bank Usage in the UK
}

\author{
RACHEL LOOPSTRA*, JASMINE FLEDDERJOHAN N**, AARON REEVES*** \\ AND DAVID STUCKLER $\mathrm{R}^{* * * *}$ \\ *Department of Nutritional Sciences, King's College London, Franklin-Wilkins Building, \\ Room 3.83, 150 Stamford St. London SE1 9NH \\ email: rachel.loopstra@kcl.ac.uk \\ ** Department of Sociology, Bowland North' Lancaster University, Lancaster LA1 4YN, United \\ Kingdom \\ email: j.fledderjohann@lancaster.ac.uk \\ *** International Inequalities Institute, London School of Economics and Political Science, \\ Houghton Street, London, WC2A $2 A E$ \\ email: a.reeves@/se.ac.uk \\ **** Department of Policy Analysis and Public Management, University of Bocconi, Via \\ Roentgen, 1 (3rdfloor), 20136 Milano, Italy \\ email: david.stuckler@unibocconi.it
}

\begin{abstract}
Since 2009, the UK has witnessed marked increases in the rate of sanctions applied to unemployment insurance claimants, as part of a wider agenda of austerity and welfare reform. In 2013, over one million sanctions were applied, stopping benefit payments for a minimum of four weeks and potentially leaving people facing economic hardship and driving them to use food banks. Here we explore whether sanctioning is associated with food bank use by linking data from The Trussell Trust Foodbank Network with records on sanctioning rates across 259 local authorities in the UK. After accounting for local authority differences and time trends, the rate of adults fed by food banks rose by an additional 3.36 adults per 100,000 (95\% CI: 1.71 to 5.01 ) as the rate of sanctioning increased by 10 per 100,000 adults. The availability of food distribution sites affected how tightly sanctioning and food bank usage were associated $(p<0.001)$; in areas with few distribution sites, rising sanctions led to smaller increases in food bank usage. In conclusion, sanctioning is closely linked with rising food bank usage, but the impact of sanctioning on household food insecurity is not fully reflected in available data.
\end{abstract}

\section{Introduction}

Insufficient and insecure household incomes, particularly short-term income losses, put households at risk of food insecurity - that is, inadequate access to food (Leete and Bania, 2010; Loopstra and Tarasuk, 2013; Ribar and Hamrick, 2003; Tarasuk et al., 2014; Huang et al., 2010). A growing body of evidence shows how government policies can either increase or reduce household food insecurity 
by changing access to social security programmes (Arteaga et al., 2016; IonescuIttu et al., 2015; Loopstra et al., 2015a; McIntyre et al., 2016).

One aspect of social security policy that may increase food insecurity among low-income households is the practice of sanctioning, which abrogates financial support to unemployed persons receiving unemployment insurance if they fail to meet criteria for seeking work. Unemployment insurance acts as a buffer against household income shocks, smoothing food consumption at the micro level (Bloemen and Stancanelli, 2005). Sanctions, in contrast, by temporarily removing this buffer, may therefore affect access to food. Yet empirical evidence on the impact of sanctioning has been limited; and so advocates of welfare conditionality have argued that sanctions encourage re-employment without exacerbating food insecurity.

This debate is particularly pertinent to the $\mathrm{UK}$, where a rapid rise in the number of people being sanctioned was concurrent with a large increase in the distribution of emergency food parcels over 2011 to 2013 following governmental efforts to increase benefit conditionality and more severely penalise non-compliance (Watts et al., 2014). The Trussell Trust - the UK's largest food bank network - has reported that sanctions are a key reason why people receive referrals to their member food banks (The Trussell Trust, 2014). Frontline food aid providers tell a similar story, reinforcing the conclusions of other investigations into food bank usage in the UK (Forsey, 2014; Perry et al., 2014).

There are reasons to be cautious of this claim, however. Food bank usage may have risen during this period regardless of any changes to welfare conditionality and sanctions. For example, food parcel distribution may have increased because the number of food banks rose (Loopstra et al., 2015c) or the number of hours the food banks were open increased. Similarly, background economic factors in the British economy, such as high unemployment, could have created additional financial pressures leading to food bank usage even if sanctions were not increasing (Lambie-Mumford and Dowler, 2015; Loopstra et al., 2016).

As highlighted in a recent UK National Audit Office (NAO) report (Comptroller and Auditor General, 2016), the impact of sanctioning on material hardship is not well-understood. Here, we ask, does temporarily stopping people's social security payments drive them to food banks? We conceptualise food bank usage as a marker of severe food insecurity in order to examine the dynamic relationship between sanctioning and food insecurity using data harmonised from 392 Trussell Trust Foodbanks in 259 local authorities over the period 2012 to 2015.

\section{Background}

Benefit conditionality and sanctioning in social security systems

Internationally, there has been increasing experimentation with using active labour market programmes to incentivise changes in behaviour among social 
security recipients (Watts et al., 2014). This is part of a wider trend of increasing welfare conditionality in social security systems, whereby individuals' entitlement to state support has become increasingly dependent on meeting an expanding number of behavioural conditions, such as regular meetings with work coaches and showing adequate evidence of job search activity, among others. These conditions vary across countries but so too does the strictness of requirements and how closely they are monitored (Venn, 2012). For example, in some countries, jobseekers are required to show job search activity only on request whereas, in others, proof must be shown to work coaches weekly or every second week.

Sanctioning penalties also differ depending on context but, generally, the threat of sanctioning (and the sanctions themselves) is assumed to incentivise unemployed persons to seek employment and reduce potential gaming behaviour (Watts et al., 2014; Venn, 2012). In many countries, sanctions are rarely applied, and countries employ warning systems to alert recipients of the potential for a sanction to be imposed. Others impose a penalty of reduced income support for only 1-2 weeks (Venn, 2012) or stop payments altogether.

The employment outcomes of sanctioning policies have been widely debated (Watts et al., 2014). Theoretically, sanctions encourage people to find work faster by increasing job search efforts among those who are sanctioned and those who want to avoid being sanctioned. Sanctions are also imposed for failure to take offered work, encouraging people to accept the first opportunity rather than waiting for a better future opportunity. Yet, quantitative studies examining employment outcomes have found mixed results, potentially because they increase the quantity not the quality of the job search and fail to take into account the nature and supply of employment opportunities available (Arni et al., 2013; Webster, 2016; Boockmann et al., 2014; Lalive et al., 2005; van der Klaauw and Van Ours, 2013). There are also concerns about the fairness of the practice (Work and Pensions Committee, 2015), given evidence that disadvantaged groups are more likely to be sanctioned than others and that sanctions may actually reduce re-employment among particular vulnerable groups (Reeves and Loopstra, 2017; Comptroller and Auditor General, 2016).

Although sanctions may improve employment-outcomes for some, they may also create health and social harms for others because they reduce incomes for people who are more likely to be financially vulnerable. Little is known about the health and social consequences of sanctioning and, in particular, about whether or not sanctioning may mean that people cannot afford basic needs, such as food. Following welfare reforms in the United States, families that had been sanctioned were more likely to have experienced poverty and inadequate access to food than families who had not been sanctioned (Cook et al., 2002; Kalil et al., 2002). Similarly, one longitudinal study of new parents found that mothers who reported their benefit payments reduced or eliminated in the past 12 months due to sanctions were more likely to report experiences of 
food insecurity for themselves and their children (Reichman et al., 2005). To our knowledge, no quantitative studies examining the relationship between welfare sanctioning polices and household food insecurity have been conducted in a European context. Given that sanctioning is now considered integral to many Western nations' social security approaches, it is critical to understand how this practice impacts access to food.

\section{Sanctions and the broader context of welfare reform}

In 2010, the Conservative-Liberal Democrat Coalition Government announced a programme of wide-sweeping reforms aimed at reducing the deficit, with a particular focus on reducing welfare costs (HM Treasury, 2010). School budgets, the NHS, and pensions were protected, but budgets for local government services, social care, and welfare benefits were reduced dramatically (De Agostini et al., 2017; Lupton et al., 2015).

Alongside targeted actions to reduce welfare spending (for example, lost or reduced entitlement to Housing Benefit and Child Benefit for some claimants, the introduction of Benefit Caps, and benefit freezes), a number of welfare reforms also made it harder for claimants to qualify, and maintain the requirements, for benefit receipt. Employment and Support Allowance (ESA) claimants were newly required to undergo Work Capability Assessments to determine their eligibility for the benefit. Those placed in the work-related activity group were additionally required to engage in work-related activity, such as job searches, work preparation schemes, and practice job interviews, in order to maintain receipt of benefits (Dwyer et al., 2016; Barr et al., 2016). Similarly, these types of conditions were intensified for lone parents claiming Income Support with children aged five or older (Johnsen, 2016). As a further move toward greater conditionality, the Claimant Commitment was introduced for Jobseeker's Allowance (JSA) claimants (Department for Work and Pensions, 2013a) and, in 2013, everyone claiming Universal Credit. These commitments, determined by Jobcentre Advisors, outline job-seeking actions that claimants must follow in order to be eligible for these benefits. Failure to meet outlined requirements means claimants are disentitled from benefits altogether or temporarily have their benefits stopped. Together, these actions, which make it harder for people to comply with benefit conditions, also mean reducing spending on welfare claims as claimants move off benefits - sometimes into work, but not always (Work and Pensions Committee, 2015; Loopstra et al., 2015b; Reeves, 2017).

As highlighted, benefit conditionality is often buttressed by sanctions for failure to comply. Although behaviour-related conditionality and accompanying sanctions are now more than 20 years old, the 2012 reforms initiated a stepchange: with the Coalition introducing one of the strictest sanctioning regimes across OECD countries. Sanctioning penalties were intensified, stopping benefit payments with immediate effect for a new minimum of four weeks, representing 


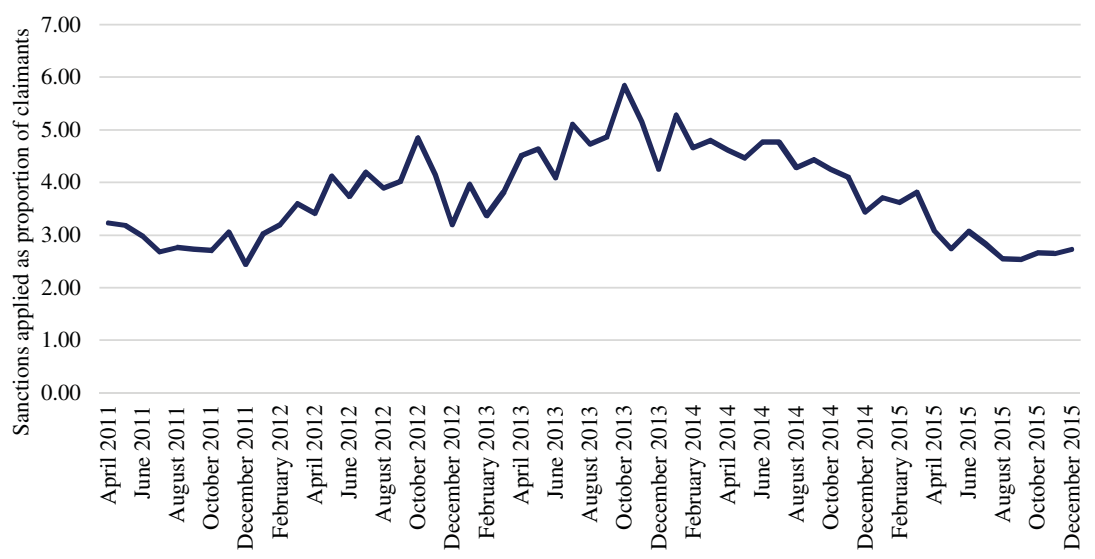

Figure 1. (Colour online) Average monthly rates of sanctioning among Jobseeker's Allowance claimants sanctioned each quarter over the period 2011 to 2015.

Notes: Graph shows number of original sanction decisions resulting in a sanction as proportion of number of people claiming Jobseeker's Allowance in England, Scotland, and Wales. Sources: Stat Xplore and Nomis

a $\mathfrak{E}_{300}$ reduction for a single claimant aged 25 or over (Comptroller and Auditor General, 2016). For more serious offences, penalty periods were extended to a minimum of 13 weeks, and up to 156 weeks (Department for Work and Pensions, 2013b).

Monthly rates of sanctions applied to claimants nearly doubled between 2009 and 2013, with about three per cent of claimants sanctioned each month in 2009 compared to over six per cent of claimants sanctioned every month in 2013 (Figure 1). This dramatic rise has been linked with the expansion of the Work Programme in 2011 and the introduction of the 2012 Welfare Reform Act (Webster, 2016), which tightened the criteria for receipt of JSA and marked an active push to increase welfare conditionalities as part of a broader agenda of creating active citizenship (Reeves and Loopstra, 2017). In 2013, over one million sanctions were applied.

\section{Welfare reform and the rise of food banks in the UK}

Welfare reform is the backdrop for the dramatic rise in food bank usage since 2010. The Trussell Trust Foodbank Network has reported rising demand for their services in recent years, evidenced by the rapid expansion of their franchise emergency food aid model, the Foodbank, and accompanying rising numbers of food parcels being distributed (Lambie-Mumford, 2013). In 2011, the Trust reported about 129,000 instances of people receiving food from their member food banks. By 2014/15, the number had climbed to almost 1.1 million (The Trussell Trust, 2015). Early examinations of the patterned growth of the network have found food banks were more likely to open in areas of higher unemployment, 
and in areas that had experienced deeper reductions in the amount of spending going out to local authorities for local services and welfare support (Loopstra et al., 2015c). These findings matched qualitative studies that found local social service agencies and community members, in the face of reduced budgets, turning to The Trussell Trust model as a source of service delivery (Lambie-Mumford, 2013). Since then, many other studies have linked demand for food banks with aspects of benefit reform, including longer wait times to receive benefit payments, the abolition of the social fund, loss of entitlements and benefit transitions (Perry et al., 2014; The Trussell Trust, 2017; Fitzpatrick et al., 2016; Garratt et al., 2016; Forsey, 2014). In-depth interviews with people using food banks conducted by Perry et al. (2014) revealed the range of challenges faced by people using food banks, such as loss of a job or partner or disability, but also noted that most often it was the acute impact of losing welfare entitlements, or the inability to access welfare in these circumstances, that led to their food bank referral. Thus, the evidence suggests that the rapid rise of food bank use from 2011, and the persistence of high rates of usage across the country since, are cumulative outcomes of the many changes to the benefit system over this period.

Quantitatively linking these changes to changing food bank usage is difficult, however, due to the number of changes that occurred, and different rollouts of the reforms geographically and over time. While the rise in food bank use matched the timing of when these reforms were rolled out (i.e. beginning in 2011 and ongoing through to 2015), at the aggregate level, the growth in numbers using food banks is hard to disentangle from new food banks beginning to operate in places where they had not been previously seen.

The intensification of conditionality and subsequent rise in sanctions is one possible exception - a discrete change in welfare receipt that can be tested using quantitative methods. The Department for Work and Pensions (DWP) data available document the number of sanctions applied to claimants each month, charting the variation in local authorities across space and time. This variation can be linked to variation in food bank use are over time within local areas. While we might expect there to be variation in the level of sanctions across areas due to differences in population characteristics, examining how rates of food bank use are associated with changes in sanctioning within a given area removes these endogenous characteristics. This enables us to track only changes in the application of sanctions - a largely exogenous source of variation arising from policy changes over this period.

\section{The uncertain link between sanctions and food bank use}

The impact of sanctioning on food bank use continues to be debated. A smallscale questionnaire delivered to people using three food banks across England found that 20-30 per cent had recently been affected by sanctions (Perry et al., 2014), but this evidence has been dismissed by policymakers. In a House of 
Commons debate in 2015, the previous Minister for Employment, Priti Patel, stated that 'there is no robust evidence that directly links sanctions and food bank use' because the 'reasons for food bank use are complex and overlapping' (HC Debate 22 June 2015 vol 595 c608). Indeed, previous studies and evidence reviews, which rely on cross-sectional and anecdotal data, have been unable to disentangle whether there is a dynamic and systematic relationship between sanctioning rates and food bank usage (Forsey, 2014; Loopstra et al., 2015c; Perry et al., 2014). Without longitudinal data, the nature of the relationship between sanctioning and food bank usage is difficult to resolve.

The problem of hidden hunger is one important issue that may contribute to uncertainty in the relationship between sanctions and food bank usage. Food insecurity underlies food bank usage (Loopstra and Tarasuk, 2012; Loopstra and Lalor, 2017), but is not regularly measured in any UK survey. In the absence of monitoring of household food insecurity in household surveys, data on food bank usage is often the only available indicator of the problem of hunger in high-income countries (Loopstra and Tarasuk, 2015). But a significant degree of hidden hunger can exist. In the case of the UK, and relevant to understanding the relationship between sanctioning and food bank usage, if someone is sanctioned and unable to afford food, their ability to access emergency food may be largely determined by the availability of a food bank distribution centre in their area. Thus, if sanction rates go up in an area where there are far fewer distribution centres, then food parcel distribution may only be weakly associated with sanctioning rates even though hunger is potentially rising. In short, hidden hunger may introduce uncertainty into the relationship between sanctioning rates and food bank usage.

Further complicating this picture is that, after 2013, the number of sanctions applied to JSA claimants in the UK declined; this is in part because the number of claimants has also declined but, even as a proportion of claimants, sanction rates have reduced (Figure 1). This fall in sanctioning has not corresponded to a decline in the aggregated number of people receiving food parcels in The Trussell Trust Network. In 2013/14, The Trussell Trust reported 913,138 instances of food parcel distribution, but in $2014 / 15$, this number increased to $1,084,604$, and further increased to $1,109,309$ in $2015 / 16$.

The disconnect in these trends is not well understood, but may be explained by two different processes. One is that the spread of the food bank network as a whole may obscure levels of rising or falling need attributable to sanctions for any specific local area because total numbers are in part driven by the availability of food banks to distribute food. Over the period 2011 to 2014, new Trussell Trust food banks opened in places where they were not operating before, which means people in need in these communities could use food banks where they were unable to before. Alternatively, food banks can also leave The Trussell Trust Network, no longer reporting the number of parcels they are distributing to the national Trussell Trust office. In short, disentangling the relationship between 
sanctions and food bank usage requires accounting for the number of food banks in these areas and should focus on the trends within these local areas. The other possible explanation is that sanctions may lead to longer term financial hardships, whereby increases in the number of sanctions applied are associated with increases in food bank usage, but declines may not equally relate to declines in food bank usage.

To explore the relationship between sanctioning and food bank use, accounting for the potential impact of the supply of food banks on this relationship, we compiled a novel database linking quarterly sanctioning rates in local authorities to area-level food bank usage data from The Trussell Trust over fiscal years 2012 to 2015. We additionally incorporated data on network characteristics to understand how the provision of food assistance influences the sanctioning-food bank usage relationship. We draw on these data to ask, how do rates of sanctioning vary with rates of food bank usage? We also explore whether declines in number of sanctions have meant fewer people needing food assistance. Lastly, we examine how the availability of Trussell Trust assistance affects the relationship between sanctioning and food bank usage. Specifically, we investigate whether the impact of sanctioning on food insecurity may not be reflected in Trussell Trust food bank usage figures where their food banks are less available, thereby providing evidence that the true impact of sanctioning on hunger is potentially obscured by the data available.

\section{Methods}

\section{Source of data}

We collected data on food bank usage from The Trussell Trust, an umbrella organisation for 424 member food banks in the UK, comprised of over 1200 distribution sites in churches or community centres (The Trussell Trust, 2016). While there are numerous food banks that operate independently in the UK, The Trussell Trust is the only franchise model that operates nationally, creating a source of comparative and harmonised data. Each member food bank is responsible for linking with local social service agencies, who then provide food bank referrals to their service users when required. Referred persons receive a food parcel meant to provide three days' worth of food for all household members.

Data from referral vouchers are entered into the central Trussell Trust database. We received access to aggregated data from each food bank in the network, collated on a quarterly basis for fiscal years 2012/13 to 2015/16. These data provide the number of instances in which adults and children received food parcels, reflecting usage volume rather than number of individuals served. The number of unique individuals helped by Trussell Trust food banks has not been tracked. We use the number of adults fed, scaled relative to the size of the local adult population, but these numbers cannot be interpreted as a quarterly 
prevalence rate, because some individuals may have received food parcels on more than one occasion in the same quarter.

We also obtained information on food bank postcodes, the year food banks were initiated, the number of distribution sites affiliated with the food bank, and the hours of operation at each distribution site from The Trussell Trust to enable description of area-level food bank operations.

\section{Sanctioning and unemployment data}

We obtained government data for local authorities in the UK on the number of people claiming JSA, the number of sanctions applied to JSA claimants, unemployment and employment rates, deprivation ranking (England only), rural-urban classification (England only) and population size from Nomis, StatXplore, and UK Government Statistics databases. Sanction data are the number of sanctions applied to claimants, summed over the months in each quarter, which were available up to the second quarter of 2015/16. Similar to food bank data, these do not pertain to individuals, so the same claimant could have received more than one sanction in the same quarter. Monthly claimant data were averaged over the quarter to provide an estimate of the quarterly claimant count. We use unemployment and employment data in our sensitivity analyses. These are aggregated data from the Annual Population Survey. At the local authority level, Nomis provides data for 12-month periods beginning every quarter.

\section{Analytic sample}

We restricted our sample to local authorities in Scotland, Wales, and England, as sanctioning data were unavailable for Northern Ireland. We excluded five local authorities with small population sizes (City of London, Isles of Scilly, Orkney Islands, Shetland Islands, and Eilean Siar). Food bank postcodes were used to link food banks to their respective local authority areas, resulting in a sum of the total number fed, sum of distribution sites operating, and sum of total operating hours for the local authority that varied across quarters. We excluded food banks and corresponding local authorities which did not consistently collect data each quarter over 2012/13 until the end of 2015/16 $(n=15)$ and also those authorities in which Trussell Trust food banks do not operate $(n=101)$. This yielded a final analytical dataset of 259 local authorities spanning 16 quarters (Web Figure A2). Descriptive statistics showing rates of feeding and the number of food banks operating for local authorities over time are shown in online supplementary material: Web Table A1 and in Web Figure A3.

\section{Statistical analysis}

First, we examined how the rate of sanctions applied in local authority populations relates to food parcel distribution. We use a fixed-effects model to control for unobserved differences across local authorities and time, asking if the 
instances of adults receiving food assistance is dynamically related to the number of sanctions applied in the population, as follows:

$$
\begin{aligned}
\text { Fed }_{\text {it }}= & \beta_{0}+\beta_{1} \text { Sanctions }_{\text {it }}+\beta_{2} \text { Claimants }_{\text {it }}+\beta_{3} \text { Season }+\beta_{4} \text { First } \\
& +\beta_{5} \text { Distribution }_{\text {it }}+\beta_{6} \text { Hours }_{\text {it }}+\mu_{i}+\varepsilon_{i t}
\end{aligned}
$$

Here, $i$ denotes the local authority and $t$ denotes the time point. Fed is the quarterly number of instances adults received food parcels per 100,000 adults in the population. Sanctions is the number of sanctions applied per 100,000 adults, and Claimants is the number of JSA claimants per 100,00o working age adults. Season is a dummy variable for first, second, third, and fourth quarters to account for seasonal trends in food parcel distribution. First is a dummy variable denoting the first quarter a food bank opened in a given local authority if it opened after April 2012. Distribution is the number of food bank distribution sites operating in a given local authority. Hours is the total number of hours food banks are open per week. $\mu_{i}$ denotes local-authority fixed-effects and $\varepsilon_{i t}$ is the random error term. In subsequent models, we include an adjustment for linear and quadratic time trends to account for secular trends in the numbers fed, sanctions applied, and JSA claimants across the UK over this time period.

Next, using a first difference model, we unpacked whether increasing sanctions from the previous quarter is associated with an increase in adult food bank usage and, in turn, whether a decline in the number of sanctions is associated with a decline in adult food bank usage, thus testing the acute dynamic relationship from quarter to quarter in numbers fed in relation to number of sanctions applied. To do this, we created two time-varying measures of sanctions: one capturing increases from the previous quarter and the other decreases. For each, changes in the opposite directions were coded as zero.

Lastly, we explored the potential problem of hidden hunger, whereby, for a given increase in the number of sanctions applied, the extent to which this may lead to food insecurity is not fully reflected in food bank usage. In places where sanctions have increased, people who experience food insecurity as a result may not be able to reach food banks where food banks are less available; this would temper an observed relationship between sanctions and food bank usage, resulting in a downward bias in our estimate of the impact of sanctions. To investigate this, we examined the interaction between change in the number of sanctions applied and the level of food bank operations in a given local authorityyear, namely the number of distribution sites and the number of operating hours.

\section{Results}

The number of operating Trussell Trust food banks increased from 138 sites in 114 local authorities in the first quarter of 2012/13 to 392 food banks in 259 local 


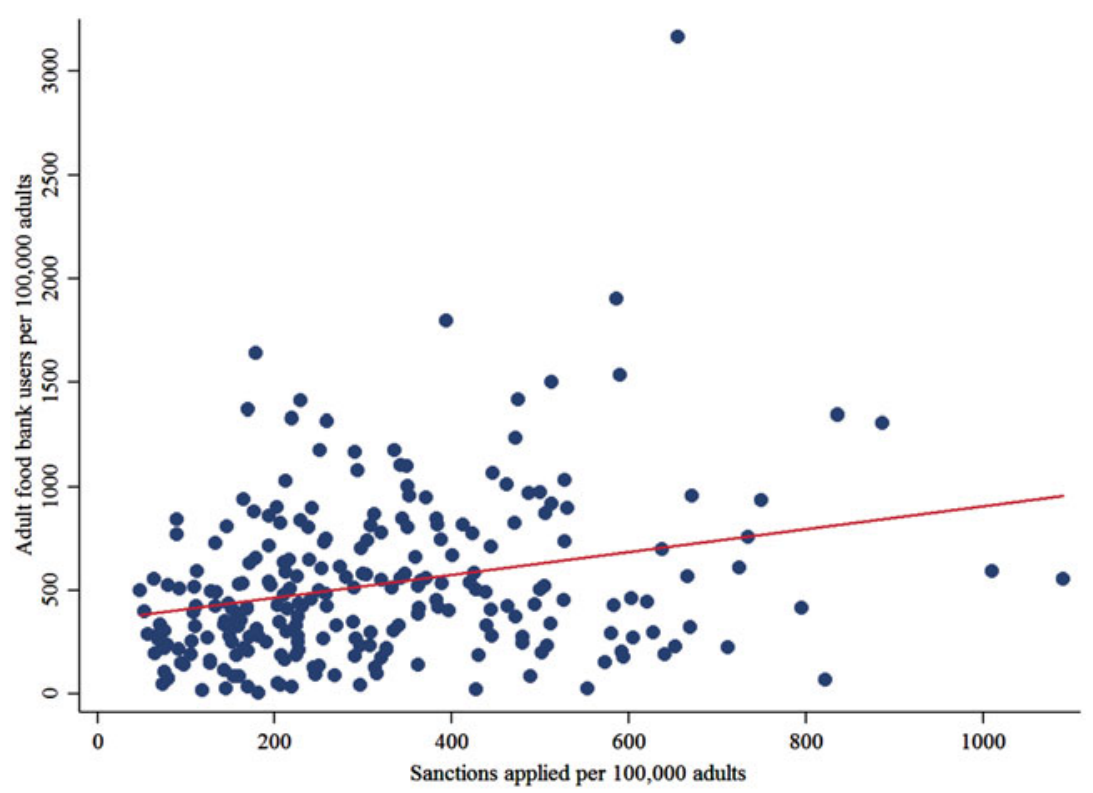

Figure 2. (Colour online) Relationship between sanctions applied and numbers of adult food bank users across local authorities with food banks, Jan-Mar 2014.

authorities in the last quarter of 2015/16 (online supplementary material: Web Table A1). The average rate of feeding across local authorities with food banks rose from about 18,855 adult users per 100,00o over the period April to June 2012, to a high of 52,468 per 100,000 over the period January to March 2014. As shown in Web Figure A2 (online supplementary material), trends in food bank usage are more telling after accounting for growth of the Network. Though food bank usage generally exhibits a growth curve, whereby usage accelerates in the first 6-12 months after food banks are launched, evidence of growth in food bank usage through 2013 and 2014 in places where food banks were already well-established and constant after 2011, suggests there was increasing demand over and above the supply of food banks between 2013 and 2014 but that, in 2015, food bank use started to decline.

Figure 2 shows the correlation between the rate of sanctions applied in local authorities and the rate of adults fed for one quarter, January to March 2014. Here, we see evidence that in places where the rate of sanctioning was higher, the rate of adult food bank usage was also higher $(\mathrm{r}=0.26$; $\mathrm{p}=<0.0001)$.

Table 1 shows how quarterly rates of food bank usage among adults related to the number of sanctions applied in the population each quarter over the period 2012 to 2015, after accounting for local authority differences. For every 10 sanctions applied per 100,00o in the population, the rate of adult food bank users was 6.44 per 100,000 adults higher ( $95 \%$ CI: 4.72 to 8.15 ). This association 
TABLE 1. Relationship between sanctions applied and number of adult food bank users in local authorities with food banks, 2012-2015.

\begin{tabular}{lccc}
\hline & \multicolumn{3}{c}{$\begin{array}{c}\text { Adult food bank users each } \\
\text { quarter per 100,000 adults }\end{array}$} \\
\cline { 2 - 5 } & $(1)$ & $(2)$ & $(3)$ \\
\hline Per 10 additional sanctions per 100,000 adults & $6.44^{* * *}$ & $6.35^{* * *}$ & $3.36^{* * *}$ \\
Per 10 additional JSA claimants per 100,000 adults & $(0.87)$ & $(0.87)$ & $(0.84)$ \\
Distribution sites per 100,00o persons & $-1.81^{* * *}$ & $-1.73^{* * *}$ & $-0.76^{* *}$ \\
Weekly hours of operation per 100,000 persons & - & $(0.20)$ & $(0.24)$ \\
Linear and quadratic time trends & - & $43.9^{* * *}$ & $33.6^{* *}$ \\
Local authority-quarters & No & -5.22 & -4.46 \\
\hline
\end{tabular}

Notes: Robust standard errors in brackets. Models include dummy variable for season, dummy variable for first quarter a food bank operated, and local authority fixed effects. Constant not shown. ${ }^{*} p<0.05,{ }^{* *} p<0.01,{ }^{* * *} p<0.001$

remained robust after adjusting for the scale of food bank operations and how long food banks had been operating (Table 1, Model 2). Lastly, we adjusted for linear and quadratic time trends. Though attenuated, the relationship between sanctioning and food bank use remained strong: for every 10 additional sanctions applied, the rate of food bank users per 100,00o was about 3.36 higher (95\% CI: 1.71 to 5.01 ).

To put these figures in context, rates of sanctioning applied in local populations rose from a mean of 302 per 100,000 adults over the April to June quarter of 2012/13 to 340 per 100,000 over the July to September quarter of 2013/14. Our model predicts this increase in JSA sanctioning would account for about 5-10 per cent of the increase in the rate of food bank usage observed over this period.

When we delineated the effects of acute increases in sanctions applied from the previous quarter from acute declines (Table 2), we observed that, for increases in sanctions, specifically, every 10 additional sanctions applied was associated with about five more adults fed in food banks (95\% CI: 3.00 to 7.40). A decline of 10 sanctions from the previous quarter was associated with a decline of about two adults fed (95\% CI: -3.23 to -0.34$)$.

Lastly, we examined how the dynamic relationship between change in sanctions applied and change in the number of adults fed was affected by the scale of food bank operations in local authorities (online supplementary material: Web Table A2). The number of distribution sites available in local authorities significantly modified the observed relationship between the change in sanctions and the change in numbers fed. This is illustrated in Figure 3. In local 
TABLE 2. Dynamic relationship between the change in number of sanctions applied from quarter-to-quarter and change in numbers using food banks.

\begin{tabular}{|c|c|c|}
\hline & \multicolumn{2}{|c|}{$\begin{array}{l}\text { Change in number of } \\
\text { adult food bank users } \\
\text { from previous quarter }\end{array}$} \\
\hline & $(1)$ & $(2)$ \\
\hline $\begin{array}{l}\text { Per } 10 \text { additional sanctions applied from previous } \\
\text { quarter }\end{array}$ & $\begin{array}{l}5.20^{* * *} \\
(1.12)\end{array}$ & - \\
\hline Per 10 fewer sanctions applied from previous quarter & - & $\begin{array}{r}-1.79^{*} \\
(0.73)\end{array}$ \\
\hline $\begin{array}{l}\text { Per } 10 \text { additional JSA claimants from previous } \\
\text { quarter }\end{array}$ & $\begin{array}{l}0.11 \\
(0.28)\end{array}$ & $\begin{array}{r}-0.038 \\
(0.28)\end{array}$ \\
\hline $\begin{array}{l}\text { Per } 1 \text { additional distribution site per 100,00o from } \\
\text { previous quarter }\end{array}$ & $\begin{array}{r}6.72^{*} \\
(3.28)\end{array}$ & $\begin{array}{c}6.28 \\
(3.24)\end{array}$ \\
\hline $\begin{array}{l}\text { Per } 1 \text { additional hour open per week per 100,000 } \\
\text { from previous quarter }\end{array}$ & $\begin{array}{r}-0.33 \\
(0.43)\end{array}$ & $\begin{array}{r}-0.32 \\
(0.44)\end{array}$ \\
\hline Local authority-quarters & 2918 & 2918 \\
\hline
\end{tabular}

Notes: Robust standard errors in brackets. Models include linear and quadratic time trends, and dummy variables for season and first quarter a food bank operated.

${ }^{*} p<0.05,{ }^{* *} p<0.01,{ }^{* * *} p<0.001$

authorities with few distribution sites per capita ( $<1$ per 100,000), if the number of sanctions increased by 20 per 100,000, there was not a corresponding significant increase in the number of adult food bank users. But for local authorities with five distribution sites or more operating per 100,000, an increase in 20 sanctions per 100,00o related to an estimated increase of about 10 more adult food bank users.

\section{Sensitivity analyses}

We performed a series of sensitivity analyses to assess the robustness of our models to alternate specifications. To test the possibility that the association between sanctions and food bank use was spurious, driven by higher rates of unemployment, we additionally adjusted our models for employment and unemployment rates and found our results unchanged (online supplementary material: Web Table A4). We also checked for outliers (i.e. observations with residuals $>$ |2SDI) and extreme observations to ensure our estimates were not being driven by these observations. No observations met our criteria for outliers. After removing observations with extreme quarterly changes in rates of feeding (i.e. $>$ the $99^{\text {th }}$ percentile), our results were unchanged (online supplementary material: Web Table A5).

We also re-ran our models using a random effects framework and adjusting for time-invariant characteristics to explore the relationship between sanctions 


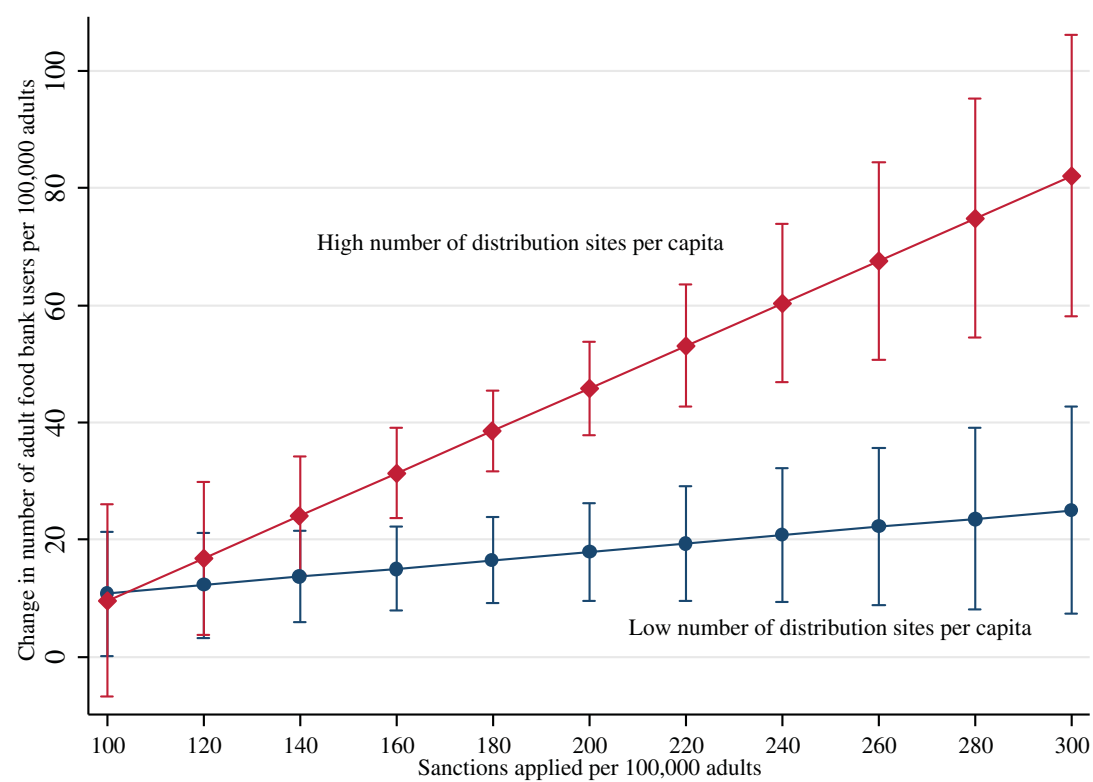

Figure 3. (Colour online) Relationship between sanctioning and adult food bank usage by concentration of food bank distribution centres in local authorities.

Notes: Graph illustrates decrease and increase from mean sanction rate of 200 applied per 100,000. High number of distribution sites refers to areas with 5 or more sites per 100,000 and low number of distribution sites refers to areas with $<1$ site per 100,000 in areas with food banks present. $\mathrm{P}$ value for interaction of change in sanctions with high distribution sites vs. low $=0.011$. For full model see Web Table A3.

and food bank use after adjusting for a wider set of area-level characteristics: specifically the Index of Multiple Deprivation, the ESA claimant rate, 2011 census data on lone parenthood and disability, and rural-urban classification. Due to many of these variables only being available for England, these models were only conducted for English local authorities (online supplementary material: Web Table A6). We found, consistent with earlier studies of these relationships (e.g. Lambie-Mumford and Green, 2017; Vidgen et al., 2016) that food bank use was higher in more deprived local authorities and with higher rates of disability and lone parenthood. However, even after adjusting for these areafactors, we observed the relationship between sanction rates and food bank use to be consistent with our fixed-effect models.

\section{Discussion}

Our findings suggest a strong, dynamic relationship exists between the number of sanctions applied in local authorities and instances of adults receiving emergency food parcels. As the quarterly rate of sanctioning rose in local authorities, the rate of adults receiving food assistance also rose. We observed that a quarter-to-quarter 
increase of 10 sanctions per 100,000 was associated with about five more instances of adults needing food, while a decline in 10 sanctions applied was associated with about two fewer instances of adults needing food. The extent to which sanctioning is reflected in demand for food assistance from The Trussell Trust depends on availability of distribution sites in a given area. Where distribution sites were not widely available to the population to use (as measured by distribution sites per capita), there was not a corresponding increase in the numbers fed, even if more people were sanctioned.

Our study uses the best current data available to examine the relationship between sanctioning and food bank usage but there are still some important limitations. We were only able to use data at the area level and so our results could be vulnerable to ecological fallacy, where rates of sanctioning correlate with food bank usage, but do not mean that the people sanctioned are the same individuals who show up in food banks. However, our area level findings are consistent with those observed among individuals in reports from frontline food assistance providers and qualitative studies (Forsey, 2014; Perry et al., 2014; Garthwaite, 2016; Fitzpatrick et al., 2016).

To our knowledge, The Trussell Trust data are the only source of longitudinal and harmonised data on food bank usage in the UK, but are influenced by factors that we could not control for. The data are a measure of volume and do not reflect the number of unique users each quarter. This may lead to variation across local areas and over time if there are differences in frequency of use between places or over time. Each member food bank also establishes relationships with local referral agencies, and these relationships are not always stable, which may affect how easily people in a given area are able to receive help from their local food bank.

Similarly, sanction data are limited by how they are recorded. While the government provides information on claims where adverse and non-adverse decisions were made and whether the decision was based on an original decision, mandatory reconsideration, or appeal, they do not provide information on the total number of original adverse decisions (Comptroller and Auditor General, 2016). These data would be important for tracking the impact of sanctions in a given quarter because, during the reconsideration and appeals process, claimants have their benefit payments stopped; the month that an appeals decision is recorded could be one or two months after a claimant first had his/her payments stopped. We based our data on original adverse decisions because we could not know with certainty that claimants had sanctions applied in these months, but using only these figures mean our estimates are likely to have underestimated the impact of sanctioning on food bank usage. Data on the number of people receiving Universal Credit, a new benefit in the UK subject to conditionality, were also not available at the time of analysis, which also means the full impact of sanctioning practices on food bank usage could not be charted. These data limitations would introduce error in our estimates that would tend to bias our 
results toward the null; however, despite these data limitations, we observed a strong and dynamic relationship between sanctioning and food bank usage.

By focussing on the acute impact of sanctions and using difference models, we have not examined the influence of other changes to social policy that appear to have played a role in the rise of food bank usage, as outlined above. While earlier analyses have examined some of these links (Loopstra et al., 2015c), as have qualitative studies (e.g. Garthwaite, 2016; Perry et al., 2014), more research is needed to further explore how welfare reforms already implemented and those ongoing, in particular the rollout of Universal Credit, may be impacting on the ability of households to afford food.

This study addresses critical gaps in the literature. Like earlier work, we find a consistent and strong positive relationship between sanctioning rates and food bank use (Loopstra et al., 2015c; Fitzpatrick et al., 2016; Garthwaite, 2016), but this work addresses limitations of these earlier papers by accounting for changes in The Trussell Trust network and cross-local variation in distribution sites. These data do not allow us to firmly establish causality but the associations we document are certainly consistent with a causal explanation. In addition, we explicitly consider what happens to people who are sanctioned in areas where there are fewer food banks. Our models suggest there are places in Britain where sanctioning rates are high but food bank usage rates are low and that appears to be the case where food aid distribution is limited, highlighting the possibility of hidden hunger, namely people who lack both financial access to food and who cannot access emergency food assistance.

Our results intervene in the ongoing debate about the drivers of rising food bank usage. Government officials have suggested sanctions have no impact on food bank use according to the evidence available (HC Debate 22 June 2015 vol 595 c608). Here, we have shown a robust empirical link between sanctioning and food bank usage. This has important policy implications. The recent decline in sanctioning is a positive sign, and is likely to have contributed to the decline in the numbers of people using food banks within local authorities in 2015/16. Yet, in 2015, there were still about 358 ,000 sanctions applied to JSA claimants, with the net cost to sanctioned jobseekers (total cost of sanctions minus hardship payments) just under $\mathfrak{E} 100$ million (Comptroller and Auditor General, 2016). We also observed that declines in sanctioning were not as strongly linked to declines in food bank usage, explaining why the decline in food bank usage has not been as fast as the decline in sanctions. This could be because experiences of sanctions trigger longer-term financial crises, such as debt accumulation. A recent report from one Trussell Trust food bank (West Cheshire) found that people who received food bank referrals for the reason of being sanctioned were more likely to have crises that lasted for three months or more (Garratt et al., 2016). It may also be the case that longer length sanctioning penalties lead to longer term food bank usage. 
It is possible sanctions may positively affect employment outcomes. A preliminary analysis of the Work Programme by the NAO found that JSA claimants who received a sanction were more likely to move into employment than those who were not sanctioned (Comptroller and Auditor General, 2016). However, conditionality and sanctions do not appear to work for everyone, potentially driving people off unemployment support entirely (Comptroller and Auditor General, 2016; Loopstra et al., 2015b). The same NAO analysis mentioned above also found that people on ESA who were sanctioned were actually less likely to return to work (Comptroller and Auditor General, 2016) while a cross-local authority analysis suggests sanctions may increase economic inactivity among people living with a disability (Reeves, 2017). This is especially relevant to people receiving help from food banks, as many are living with mental or physical ill health (Loopstra and Lalor, 2017). However, data that enable employment and hardship outcomes to be tracked, among claimants who are sanctioned and those who are not, are needed for more robust analyses of the potential costs of benefit sanctions alongside potential benefits (Comptroller and Auditor General, 2016).

Tracking the effects of sanctions will become even more essential with the introduction of in-work conditionality for Universal Credit claimants, which has raised concerns that more people will be exposed to sanctions, making these findings highly relevant to an increasing number of benefit claimants in the UK (Welfare Conditionality, 2016).

Our results also have relevance for the providers of charitable food assistance and the wider problem of food insecurity in the UK. It is likely that Trussell Trust data only capture a fraction of people who experience food insecurity; our results suggest there could be hidden hunger due to sanctioning in places where Trussell Trust food banks are not available. People in these areas may instead seek help from other agencies or non-Trussell Trust food banks, but these numbers are not reflected in Trussell Trust data. Despite known limitations of this measure (Loopstra and Tarasuk, 2015), this is currently the only longitudinal indicator of household food insecurity across areas in the UK. The Poverty and Social Exclusion survey includes an item asking whether households can afford to eat two meals a day, and this figure rose from 1 per cent to 3 per cent over the period 1999 to 2012; however, the long time lag between surveys (with an intermediate time point in 2005) and the small-scale nature of the survey means it cannot be used to track changes over time or local areas. Further, the measurement of household food insecurity should involve multi-item scales that capture the chronicity and severity of experiences of household food insecurity since it is often experienced intermittently or cyclically. A recent cross-sectional survey of adults in the UK (Bates et al., 2017) did include the internationally validated USDA Adult Food Security Scale, and found that 8 per cent of adults were moderately or severely food insecure (equating to an estimated four million adults). In contrast, Trussell Trust estimated that 500,000 unique adults and children were using their 
food banks over 2014/15. This discrepancy highlights how important it is for the UK to implement household food insecurity monitoring.

Our findings also highlight the limitations of any charitable food support network's ability to eradicate food insecurity. These networks are increasingly relied upon to fill in the gaps in welfare support but, by relying on volunteers and donated food and space to operate, they will vary in their capacity to address hunger in their area (Lambie-Mumford, 2013; Lambie-Mumford, 2016). As such, they are not equipped to address these gaps in every part of the country and are less able to respond quickly to changes in need.

These observations point to several directions for future research. The incorporation of household food insecurity and food bank usage monitoring into routine surveys conducted in the UK would enable individual analyses of the causes and consequences of these experiences. There is also a need for harmonised data collection across short-term providers of emergency assistance to enable better identification of where there may be gaps in the provision of emergency support and to enable evaluation of the impact of this support on the wider problem of food insecurity. Lastly, food bank usage is one possible harm associated with sanctioning, but other potential outcomes include declines in mental health, debt, and even death (Gentleman, 2014). Longitudinal studies of benefit claimants would enable better understanding of how prevalent sanctioning is and what types of outcomes are associated with this practice.

\section{Acknowledgements}

We would like to thank members of our advisory group who provided feedback on early drafts of the paper.

\section{Financial support}

This research was funded by a grant provided by the Trussell Trust Foodbank Network. Rachel Loopstra and David Stuckler were supported by a Wellcome Trust Investigator Award during the course of this research. Rachel Loopstra is supported by an ESRC research fellowship. The research question, design, analyses, and writing were solely devised by the study authors. The views expressed reflect only the authors' interpretations of the findings.

\section{Supplementary material}

To view supplementary material for this article, please visit https://doi.org/10. 1017/So047279417000915

\section{References}

Arni, P., Lalive, R. and Van Ours, J.C. (2013), 'How Effective Are Unemployment Benefit Sanctions? Looking Beyond Unemployment Exit', Journal of Applied Econometrics, 28: $1153-1178$. 
Arteaga, I., Heflin, C. and Gable, S. (2016), 'The impact of aging out of WIC on food security in households with children', Children and Youth Services Review, 69: 82-96.

Barr, B., Taylor-Robinson, D., Stuckler, D., et al. (2016), 'Fit-for-work or fit-for-unemployment? Does the reassessment of disability benefit claimants using a tougher work capability assessment help people into work?', Journal of Epidemiology and Community Health, 70:452-458.

Bates, B., Roberts, C., Lepps, H., et al. (2017), 'The Food \& You Survey Wave 4', London: Crown Copyright.

Bloemen, H.G. and Stancanelli, E.G.F. (2005), 'Financial Wealth, Consumption Smoothing and Income Shocks Arising from Job Loss.', Economica, 72: 431-452.

Boockmann, B., Thomsen, S.L. and Walter, T. (2014), 'Intensifying the use of benefit sanctions: an effective tool to increase employment?' IZA Journal of Labor Policy, 3 (1): 1-19.

Comptroller and Auditor General. (2016), Benefit Sanctions. London: National Audit Office.

Cook, J.T., Frank, D.A., Berkowitz, C., et al. (2002), 'Welfare reform and the health of young children: a sentinel survey in 6 US cities', Arch Pediatr Adolesc Med, 156: 678-684.

De Agostini, P., Hills, J. and Sutherland, H. (2017), 'Were we really all in it together? The distributional effects of the 2010-15 UK Coalition Government's tax-benefit policy changes', Social Policy \& Administration, Online first: 6 September 2017.

Department for Work and Pensions (2013a), Claimant Commitment to spell out what jobseekers must do in return for benefits. London: Gov.uk.

Department for Work and Pensions (2013b), 'Jobseeker's Allowance: overview of revised sanctions regime', London: Department for Work and Pensions, https://www.gov.uk/ government/uploads/system/uploads/attachment_data/file/238839/jsa-overview-ofrevised-sanctions-regime.pdf. [ accessed 13/12/16].

Dwyer, P., Jones, K., McNeil, J., et al. (2016), 'First wave findings: disability and conditionality', York: University of York.

Fitzpatrick, S., Bramley, G., Sosenko, F., et al. (2016a), 'Destitution in the UK', York: Joseph Rowntree Foundation.

Forsey, A. (2014), 'An evidence review for the All-Party Parliamentary Inquiry into Hunger in the United Kingdom', London: All Party Parliamentary Group Inquiry into Hunger.

Garratt, E., Spencer, A. and Ogden, C. (2016), '\#stillhungry: who is hungry, for how long, and why?' West Cheshire: West Cheshire Trussell Trust Foodbank.

Garthwaite, K. (2016), Hunger pains, Bristol: Policy Press.

Gentleman, A. (2014), “"No one should die penniless and alone”: the victims of Britain's harsh welfare sanctions', The Guardian, 3/8/2014.

HC Debate, 22 June 2015, vol 595 c608. Food Banks: Written question - 900461.

HM Treasury (2010), Spending Review 2010. London: Crown Copyright.

Huang, J., Guo, B. and Kim, Y. (2010), 'Food insecurity and disability: do economic resources matter?' Social Science Research, 39: 111-124.

Ionescu-Ittu, R., Glymour, M. M. and Kaufman, J.S. (2015), 'A difference-in-differences approach to estimate the effect of income-supplementation on food insecurity', Preventive Medicine, 70: 108-116.

Johnsen, S. (2016), 'First wave findings: Lone parents. Welfare conditionality: sanctions, support, and behaviour change' York: University of York.

Kalil, A., Seefeldt, K.S. and Wang, H.C. (2002), 'Sanctions and material hardship under TANF', Social Service Review, 76: 642-662.

Lalive, R., Zweimuller, J. and van Ours, J.C. (2005), 'The effect of benefit sanctions on the duration of unemployment', Journal of the European Economic Association, 3: 1386-1417.

Lambie-Mumford, H. (2013), "Every Town Should Have One": Emergency Food Banking in the UK', Journal of Social Policy, 42: 73-89.

Lambie-Mumford, H. (2016), 'The rise of food charity: issues and challenges' Geography, 101: $11-16$.

Lambie-Mumford, H. and Dowler, E. (2015), 'Hunger, Food Charity and Social Policy Challenges Faced by the Emerging Evidence Base', Social Policy and Society, 14: 497-506. 
Lambie-Mumford, H. and Green, M.A. (2017), 'Austerity, welfare reform and the rising use of food banks by children in England and Wales', Area, 49: 273-279.

Leete, L. and Bania, N. (2010), 'The effect of income shocks on food insufficiency', Review of Economics of the Household, 8: 505-526.

Loopstra, R., Dachner, N. and Tarasuk, V. (2015a), 'An exploration of the unprecedented decline in the prevalence of household food insecurity in Newfoundland and Labrador, 20072012', Canadian Public Policy, 41: 191-206.

Loopstra, R. and Lalor, D. (2017), 'Financial insecurity, food insecurity, and disability: the profile of people receiving emergency food assistance from The Trussell Trust Foodbank Network in Britain', London: The Trussell Trust.

Loopstra, R., Reeves, A., McKee, M., et al. (2015b), 'Working paper: Do punitive approaches to unemployment benefit recipients increase welfare exit and employment? A cross-area analysis of UK sanctioning reforms', Oxford: University of Oxford.

Loopstra, R., Reeves, A., McKee, M., et al. (2016), 'Food insecurity and social protection in Europe: Quasi-natural experiment of Europe's great recessions 2004-2012', Preventive Medicine, 89: 44-50.

Loopstra, R., Reeves, A., Taylor-Robinson, D., et al. (2015c), 'Austerity, sanctions, and the rise of food banks in the UK', British Medical Journal, 350: h1775.

Loopstra, R. and Tarasuk, V. (2012), 'The relationship between food banks and household food insecurity among low income Toronto families', Canadian Public Policy, 38: 497514 .

Loopstra, R. and Tarasuk, V. (2013), 'Severity of household food insecurity is sensitive to change in household income and employment status among low-income families', Journal of Nutriton, 143: 1316-1323.

Loopstra, R. and Tarasuk, V. (2015), 'Food Bank Usage Is a Poor Indicator of Food Insecurity: Insights from Canada', Social Policy and Society, 14: 443-455.

Lupton, R., Burchardt, T., Fitzgerald, A., et al. (2015), 'The Coalition's Social Policy Record: Policy, Spending and Outcomes 2010-2015', London: Centre for Analysis of Social Policy.

McIntyre, L., Dutton, D.J., Kwok, C., et al. (2016), 'Reduction of Food Insecurity among Lowincome Canadian Seniors as a Likely Impact of a Guaranteed Annual Income', Canadian Public Policy, 42: 274-286.

Perry, J., Williams, M., Sefton, T., et al. (2014), 'Emergency use only: Understanding and reducing the use of food banks in the UK', London: Oxfam GB.

Reeves, A. (2017), 'Does sanctioning disabled claimants of unemployment insurance increase labour market inactivity? An analysis of 346 British local authorities between 2009 and 2014', Journal of Poverty and Social Justice, 25: 129-146.

Reeves, A. and Loopstra, R. (2017), “'Set up to Fail?” How Welfare Conditionality Undermines Citizenship for Vulnerable Groups', Social Policy and Society, 16: 327-338

Reichman, N. E., Teitler, J. O. and Curtis, M. A. (2005), 'TANF sanctioning and hardship', Social Service Review, 79: 215-236.

Ribar, D.C. and Hamrick, K.S. (2003), 'Dynamics of Poverty and Food Sufficiency. Food Assistance and Nutrition Research Report', Washington, D.C.: United States Department of Agriculture, Economic Research Service.

Tarasuk, V., Mitchell, A. and Dachner, N. (2014), 'Household food insecurity in Canada: 2012' Toronto: University of Toronto.

The Trussell Trust. (2014), 'Evidence submitted to the Work and Pensions Select Committee Inquiry into Benefit Sanctions', Salisbury: The Trussell Trust.

The Trussell Trust. (2015), 'Foodbank use tops one million for first time says Trussell Trust' London: The Trussell Trust,22 April.

The Trussell Trust. (2016), 'What We Do: The Trussell Trust partners with local communities to help stop UK hunger', https://www.trusselltrust.org/what-we-do/, [ accessed 13/12/16].

The Trussell Trust. (2017), 'UK foodbank use continues to rise', London: The Trussell Trust,25 April. 
Van der Klaauw, B. and Van Ours, J.C. (2013), 'Carrot and Stick: How Re-Employment Bonuses and Benefit Sanctions Affect Exit Rates from Welfare', Journal of Applied Econometrics, 28: $275-296$.

Venn, D. (2012), 'Eligibility criteria for unemployment benefits: quantitative indicators for OECD and EU Countries', Paris: OECD.

Vidgen, R., Hamflett, A., Hindle, G., et al. (2016), 'Business analytics development in the food bank sector- Phase Two Report', Hull: University of Hull.

Watts, B., Fitzpatrick, S., Bramley, G., et al. (2014), 'Welfare sanctions and conditionality in the UK', York: Joseph Rowntree Foundation.

Webster, D. (2016), 'Benefit sanctions have failed: a Comprehensive Review is needed', http://blogs.lse.ac.uk/politicsandpolicy/benefit-sanctions-have-failed-a-comprehensivereview-is-needed/, [ accessed 13/12/17].

Welfare Conditionality (2016), 'Written evidence from the Welfare Conditionality: Sanctions, Support and Behaviour Change Project. Submission to Work and Pensions Select Committee inquiry: Universal Credit “in-work progression”, York: Welfare Conditionality.

Work and Pensions Committee (2015), 'Benefit sanctions policy beyond the Oakley Review', London: Department for Work and Pensions. 